\title{
Autonomy and Intervention in Medical Practice
}

\author{
Jianli Song \\ Marxism School, Xiamen University, Xiamen, China \\ Email: songjl@xmu.edu.cn
}

How to cite this paper: Song, J. L. (2018). Autonomy and Intervention in Medical Practice. Open Journal of Philosophy, 8 , 294-307.

https://doi.org/10.4236/ojpp.2018.83021

Received: October 9, 2017

Accepted: May 26, 2018

Published: May 29, 2018

Copyright $\odot 2018$ by author and Scientific Research Publishing Inc. This work is licensed under the Creative Commons Attribution International License (CC BY 4.0).

http://creativecommons.org/licenses/by/4.0/

\begin{abstract}
Autonomy and intervention are two terms of Political philosophy, and they have always been essentially located polar opposites of each other. But in medical practice, it is problematic to stress alone that either side. We should get rid of abstract liberal individual right thinking and reconsider the relationship between the patients and the physicians in all kinds of real situations. Only if we truly worship and praise for the life, including more moral and humanistic concern in abstract right discourse, the more elastic the ethical decision model will be aroused in current medical practice.
\end{abstract}

\section{Keywords}

Autonomy, Intervention, Life, Dignity, Justice

\section{Introduction}

In health care contexts, patient autonomy is highly valued, wherein respect for autonomy is usually associated with allowing or enabling patients to make their own decisions about which health care interventions they will or will not receive. By analyzing specific conflict situations between the patient's autonomy and the physician's intervention from within different cultural backgrounds, this paper suggests that a strong focus on the patients' independence can be problematic. At the same time, both excessive and insufficient intervention can be considered unjust.

For example, in China, a pregnant woman named Li-Yun Lee and her fetus were both dead in Hospital in Beijing, just because her husband Zhi-Jun Xiao refused to sign his name on the hospital's caesarean operation notice. The physicians and nurses were helpless even they want to save. This case highlights in China the conflict between medical intervention and a patient's (especially a family member's) autonomy often manifest as the physician's insufficient inter- 
vention and the patient herself lacks autonomy. But in western medical practice, there are different conditions about autonomy. Negative autonomy is the right to "refuse" specific medical measures, whereas positive autonomy is the hope of "obtaining" specific medical measures. At present, there are fewer and fewer restrictions regarding negative autonomy world-wide. It is well known that the landmark Quinlan case and similar cases were instrumental in creating the so-called "Great American Consensus". Patients have the right without any restrictions to refuse any medical treatment as long as they don't want this kind of treatment, even if the treatment is necessary to sustain patients' lives. Different from negative autonomy, there are widely debates about positive autonomy, just as Gilgunn case told us. Catherine F. Gilgunn who became comatose and suffered irreversible neurological damage, Mrs. Gilgunn died on Aug. 10, 1989, after her doctors at the hospital issued a "do-not-resuscitate order" over Miss Gilgunn's objections. Miss Gilgunn sued, saying the doctors were obligated to abide by her mother's wishes that she was kept alive as long as possible. This case highlights that patients" over self-determination will result in "autonomy gone amuck" in European and American countries.

I do not question the importance of autonomy in ethical conduct. I just want to say that a strong focus on making the right decisions is problematic, especially when combined with a tendency to stress the importance of patients' independence in choosing their treatment. It distracts attention from other important aspects of life and poses challenges to autonomy in health care. Firstly, there are many factors which obstruct the realization of patient autonomy. Secondly, each patient is subject to specific health care system. Thirdly, each patient is not only a living person in the physical sense, but also in the spiritual one. So it's time to add medical background justice and emotional care into a philosophy of rights. Just think, if emotional care and love infiltrated the medical practice everywhere, would there still be serious conflicts between patients and physicians? On the contrary, if interventions are always filled with injustice and impersonal medical technology, no matter what kind of advanced treatment is being used, patients may be unable to truly experience the dignity of life.

In medical practice, the balance between patient autonomy and moderate medical intervention ultimately depends on a kind of consensus between physician and patient based on principles of social justice. Only in this way can we eliminate the crisis of autonomy versus intervention and move toward greater cooperation between physician and patient.

\section{Autonomy and Intervention in Western Medical Practice}

The earliest physician-patient relationship was based on the patriarchal ideology, with decision-making residing squarely with the physician. During World War II, Nazi doctors destroyed human lives with their systematic research experiments, shaking patients' trust in doctors. In order to avoid the improper violation of doctor decision-making power, the Nuremberg code established the 
principle of informed consent, establishing that patient autonomy and medical decision making belonged to the patient. ${ }^{1}$

The term "autonomy" stems from the Greek word auto (self) and nomos (law). In medical practice, it refers to "everyone is free to arrange their life according to his or her own desire" (Rae \& Cox, 1999) which includes the patient's independence, self-reliance and the capacity to make his or her own decisions. This respect for autonomy is also invoked in discussions about confidentiality, fidelity, privacy and truth-telling, but it is most strongly associated with the idea that patients should be allowed or enabled to make autonomous decisions about their health care.

Beauchamp and Childress' influential definition identifies autonomous decisions as those made intentionally and with substantial understanding and freedom from controlling influences (Beauchamp \& Childress, 1989). The core of the autonomy principle is respect for human rights, including informed consent, privacy protection, keeping secrets, etc. Usually in medical treatment activity, the patient's autonomy is mainly manifested as autonomous choice and autonomous acts. Autonomous choice means individual decision making is completely free. Patients can make choices that meet with their own interests according to their own will, while autonomous acts emphasize personal capacity, whether patients have the capacity to understand substantial information, form a judgment according to their own values and communicate with the physician freely about their wishes. Thus we say patients have a decision making capacity (Beauchamp \& Childress, 2001).

A physician's intervention is also known as Paternalism in medical practice, that means the doctor knows best, the doctor chooses best, the doctor does best-all in keeping with the welfare of the patient. Generally, a physician's intervention refers to some action taken by a physician so as to limit the patient's autonomy when there are conflicts between patient autonomy and other principles such as the principle of life, of beneficence, of "doing no harm" and the principle of public welfare and so on (Qiu \& Sun, 2008), meant to maximize the patient's interests.

So, on the one hand, physicians have the right to decline patients' unreasonable requests which might violate rules of medical science. On the other hand, medical intervention must also respect patient autonomy. According to "Convention on Human Rights and Biomedicine" (Council of Europe, 2009), an intervention in the health field may only be carried out after the person concerned has given free and informed consent to it. This person shall beforehand be given appropriate information as to the purpose and nature of the intervention as well

${ }^{1}$ The Nuremberg Code is the most important document in the history of the ethics of medical research. The Code was formulated in August 1947, in Nuremberg, Germany, by American judges sitting in judgment of Nazi doctors accused of conducting murderous and torturous human experiments in the concentration camps (the so-called Doctors' Trial). The judges articulated a sophisticated set of 10 research principles centered not on the physician but on the research subject. These principles, which we know as the Nuremberg Code, included a new, comprehensive, and absolute requirement of informed consent (principle 1), and a new right of the subject to withdraw from participation in an experiment (principle 9). It served as a blueprint for today's principles that ensure the rights of subjects in medical research. More detailed information in (Shuster, 1997). 
as on its consequences and risks. The person concerned may freely withdraw consent at any time. In the case of protection of persons not able to consent, the implementation of medical intervention should satisfy three conditions as follow: firstly, an intervention may only be carried out on a person who does not have the capacity to consent, for his or her direct benefit (Convention on $\mathrm{Hu}$ man Rights and Biomedicine, Chapter II, Article 6, 2009). Secondly, the previously expressed wishes relating to a medical intervention by a patient who is not, at the time of the intervention, in a state to express his or her wishes shall be taken into account (Convention on Human Rights and Biomedicine, Chapter II, Article 9, 2009). Thirdly, where, according to law, an adult does not have the capacity to consent to an intervention because of a mental disability, a disease or for similar reasons, the intervention may only be carried out with the authorization of his or her representative or an authority or a person or body provided for by law. The individual concerned shall as far as possible take part in the authorization procedure (Convention on Human Rights and Biomedicine, Chapter II, Article 6, 2009).

In Western medical practice, there are two kinds of autonomy. One is negative autonomy, the other is positive autonomy. The former is the right to "refuse" specific medical measures, whereas the latter is the hope of "obtaining" specific medical measures. At present, there are fewer and fewer restrictions regarding negative autonomy world-wide, where we can get a glimpse of the tendency from the following cases. Karen Ann Quinlan was 21 years old in 1975. After a night of drinking alcohol and ingesting tranquilizers, Quinlan passed out and ceased breathing for two 15-minute periods. After it was determined that she was in a persistent vegetative state, her father wished to remove her from the artificial ventilator. Quinlan's primary physician and the hospital both refused. Quinlan's father filed suit in the New Jersey Superior Court to be appointed Quinlan's guardian so that he could act on her behalf, but the Court denied his request (Milwaukee Journal, 1975). Mr. Quinlan appealed the decision, and the New Jersey Supreme Court, on March 31, 1976, held that he could authorize the cessation of ventilation, and the hospital was bound to proceed with this order.

The landmark Quinlan case and similar cases ${ }^{2}$ were instrumental in creating the so-called "Great American Consensus". Patients have the right without any

${ }^{2}$ Cruzan v. Director, Missouri Department of Health: On January 11, 1983, Nancy Cruzan lost control of her car. She was thrown from the vehicle and landed face-down in a water-filled ditch. Paramedics found her with no vital signs, but they resuscitated her. After three weeks in a coma, she was diagnosed as being in a persistent vegetative state (PVS). Surgeons inserted a feeding tube for her long-term care. The issue of this case was whether the State of Missouri had the right to require "clear and convincing evidence" in order for the Cruzans to remove their child from life support. In a 5-4 court decision, the Court found in favor of the Missouri Dept. of Health. However, it upheld the legal standard that competent persons are able to exercise the right to refuse medical treatment under the Due Process Clause and its implied right to privacy. Because there was no "clear and convincing evidence" of what Nancy Cruzan wanted, the Court upheld the state's policy. After the case was decided the family went back and found more proof that Nancy Cruzan would have wanted her life support terminated and eventually won a court order to have her removed from life support. Cruzan died 11 days later on December 26, 1990. This decision has, while not directly, influenced many other cases. (Text of Cruzan v. Director, Missouri Department of Health, 497 U.S. 261 (1990); The Terri Schiavo case was a legal struggle involving prolonged life support in the United States that lasted from 1990 to 2005. The issue was whether to carry out the decision of the husband of Teresa Marie "Terri" Schiavo to terminate life support for her. Terri was diagnosed by doctors as being in a persistent vegetative state. The highly publicized and prolonged series of legal challenges presented by her parents and by state and federal legislative intervention affected a seven-year delay before life support finally was terminated (Shepherd, 2006: pp. 297-311). 
restrictions to refuse any medical treatment as long as they don't want this kind of treatment, even if the treatment is necessary to sustain patients' lives (Truog, 2008). In 1990, the US Congress enacted the Patient Self-Determination Act which ensures a patient's right to refuse medical treatment and establishes the legal state of Advance Directive to guarantee patients' desire can still be put into effect after they have lost consciousness.

Generally, specialists in European and American academic circles and medical fields are always cautious about positive autonomy. They believe that positive autonomy shouldn't be blindly expanded. For example, based on the revised concept of autonomy ${ }^{3}$, O'Neill considers that "conceptions of individual autonomy cannot provide a sufficient and convincing starting point for bioethics, or even for medical ethics". She concludes, "The supposed triumph of individual autonomy over other principles-is an unsustainable illusion” (O’Neill, 2002). Following O'Neill's revised concept of autonomy, Gill points out that the paradigm of individual autonomy has become dominant in bioethics recently and concurs that it is an aberrant application and that conceptions of individual autonomy cannot provide a sufficient and convincing starting point for ethics within medical practice. That is, the dominance of the individual autonomy paradigm has indeed harmed physician-patient relationship. Although it seems to eliminate any residue of medical paternalism, we suggest that it has tended to replace it with an equally (or possibly even more) unacceptable bioethical paternalism. In addition it may, for example, lead some doctors to consider mistakenly that unthinking acquiescence to a requested intervention against their clinical judgment is honoring "patient autonomy" when it is, in fact, an abrogation of their duty as doctors (Stirrat \& Gill, 2005).

An extreme form of Positive Autonomy goes like this: doctors may think they don't have to continue performing CPR on a patient but the patient's family acting on behalf of the patient thinks differently. Here is a conflict between doctors wanting to do what is best for the patient and not provide futile care and prolong suffering when the families want to carry on. A famous case of a court ruling on limits of rights of patients is Gilgunn v. Massachusetts General Hospital. The case, which went to trial in the Superior Court of Massachusetts on April 4, involved an elderly woman, Catherine F. Gilgunn, who became comatose and suffered irreversible neurological damage while a patient at Massachusetts General Hospital. Mrs. Gilgunn's daughter, Joan Gilgunn, said her mother had always wanted everything medically possible to be done for her if

${ }^{3} \mathrm{O}^{\prime}$ Neill entitles this "principled autonomy" (which we will contrast with "individualistic autonomy"). In Kant's account of moral autonomy "there can be no possibility of freedom for any one individual if that person acts without reference to all other moral agents" (Campbell, 1995). "Kantian autonomy is manifested in a life in which duties are met, in which there is a respect for others and their rights". Kant's view of autonomy is not "a form of self expression", but "rather a matter of acting on certain sorts of principles, and specifically on principles of obligation". "Mill's version of autonomy", she asserts, "sees individuals not merely as choosing to implement whatever desires they happen to have at a given moment, but as taking charge of those desires, as reflecting on and selecting among them in distinctive ways." (O’Neill, 2002) 
she became incompetent. Mrs. Gilgunn died on Aug. 10, 1989, after her doctors at the hospital issued a "do-not-resuscitate order" over Miss Gilgunn's objections. Miss Gilgunn sued, saying the doctors were obligated to abide by her mother's wishes that she be kept alive as long as possible. Massachusetts court ruled ultimately that the hospital and its doctors need not provide care they deem futile, even if a patient has asked for it (Kolata, 1995). As to the patient's requirement of futile treatment like this, a lot of people think that such patients' self-determination was “autonomy gone amuck" (Truog, 2008). This statement is based on the following view. Although the principle of beneficence and the principle of "do no harm" are all requests for physicians to carry out obligations to provide treatment for patients so as to relieve their pain, regain their health or postpone their death, sometimes providing treatment does not necessarily meet with the interests of the patient. Any kind of examination, remedy or medical treatment can potentially produce risks or side-effects, so, either making patients suffer unnecessary risk or making patients receive some examination or treatment which obviously does not benefit them can all possibly go against the principle of beneficence and the principle of "do no harm".

Viewed from the overall development of medical practice in Europe and the United States, there are relatively sound medical legislation systems and relatively clear rights and duties among physicians, patients and patients' families. As long as the patient's true wishes are being affirmed, their negative autonomy is easily justified under the premise of respect for patients' (or their agent's) desires. As a result, there is little conflict between doctor intervention and family autonomy, so that absolutizing negative autonomy has increasingly become a tendency. Certainly, whether the patient's mind is normal or not and whether they have adhered to the principles of autonomy are all important elements which are deliberated by every country's set ethics and laws. On the contrary, positive autonomy often needs to be balanced with medical intervention, that is, the patient's positive autonomy must maintain a balance with the professional advice of his or her medical team. For example, when a patient over-demands futile treatment ${ }^{4}$, the medical team shall have the right to refuse treatment. Therefore, to some extent, the development of patient's positive autonomy will result in a conflict between the doctor's determination and the patient's (or family members') autonomy, but this kind of conflict is seldom further upgraded to serious medical disputes due to the intervention of an authoritative intermediary

\footnotetext{
${ }^{4}$ Futility is defined as "inadequacy to produce a result or bring about a required end; ineffectiveness". Medically, the concept of "futility," according to the American Medical Association, "cannot be meaningfully defined" (Opinion 2.035 Futile Care, 2008). In general, a medically futile treatment is an action, intervention, or procedure that might be physiologically effective in a given case, but cannot benefit the patient, no matter how often it is repeated. A futile treatment is not necessarily ineffective, but it is worthless, either because the medical action itself is futile (no matter what the patient's condition) or the condition of the patient makes it futile (Drane \& Coulehan, 1993). In medical futility cases the patient or surrogate wants to pursue the goal of preserving life even if there is little chance or no hope of future improvement, while the other party, the physician, sees dying as inevitable and wishes to pursue the goal of comfort care. For a more detailed analysis, see (Council on Ethical and Judician Affairs, American Medical Association, 1999).
} 
institution such as a medical ethics committee and so on.

\section{Autonomy and Its Ethical Dilemmas in Chinese Medical Practice}

In China, the medical legislation system and protective mechanisms aimed at physicians' decisions are relatively weak. Physicians often have to succumb to realistic considerations when facing medical decisions in the matter of patients' life and death. Coupled with an ill-defined "priority sequence" between patients and their family, the recognition of patient autonomy is more complex compared with European and American countries.

Let's first look at a case. On November 21, 2007, a pregnant woman named is Li-Yun Lee was rushed to Chaoyang Hospital in Beijing by her husband Zhi-Jun Xiao. However, faced with a dying pregnant wife, Zhi-Jun Xiao refused to sign his name on the hospital's caesarean operation notice, saying he disagreed with caesarean operations and was willing to bear all consequences. The physicians and nurses were helpless, and the hospital decided to respect the right of informed consent and give up on surgery. Three hours later, the pregnant woman and her fetus were both dead. This case highlights the conflict between medical intervention and a patient's (especially a family member's) autonomy. Many people deplored the fact that the hospital ignored the patient's right to life and failed to exercise their right of medical intervention in order to save the woman's life. But physicians also have their reasons, without relevant legislation to support, how can they to operate surgery regardless of family members' objections? Saving lives is a physician's duty, while patients also have the right to defend their own interests. Some of time, patients will sue physician and hospital for "tort". To avoid trouble, physicians are afraid to make a claim to save the patient without the consent of the family and the legal authority.

The following is article 56 of the tort liability law of the People's Republic of China promulgated in July 2010: in emergency situations such as rescuing critically ill patients, if it is impossible to get the consent of the patients or their close relatives, then the hospital has the authority to implement appropriate health care measures following approval by the head of the medical institution. This is the strongest Chinese legislation on medical intervention. However, there remains a point of contention. If patients or their family have definitely refused treatment, namely "do not agree with treatment", do physicians still have the right of medical intervention to save the patient's life regardless of the patient's (and family member's) right of informed consent? That's exactly why they said hospital had to give up its right of medical intervention in the case above.

In European and American countries, usually only a patient's own signature is required, and the family member's signature is needed only in special circumstances. In emergency cases, all doctors have an obligation to rescue patients immediately regardless of whether there is a signature or not. In China, however, according to article 33 formulated in "The regulation of medical institutions" promulgated in 1994, prior to an operation one must obtain the consent of the 
patient, and the signature of family members or related parties. Even if there are more detailed provisions in the newer article 56, it is still not clear how physicians should exercise medical interventions when the patient (or patient's family member) are well-informed but happen to disagree. Therefore, in accordance with legal requirements, the hospital abided by the relevant laws and regulations, that is, the hospital had no choice but to give up on surgery without the signature of Zhi-Jun Xiao. But in this case, not only was the patient's right to life not respected, but the physician's right of intervention was greatly limited.

In contrast to the individualism prevalent in European and American cultures, in China the patient's right of informed consent is often linked to family members, that is, it is impossible to ignore the opinion of "near relatives" when it comes to patients exercising their rights. In most cases, "near relatives" will respect the patient's will, but sometimes there will be serious disagreements between "near relatives" and the patients themselves.

Faced with these conflicts, medical treatment may go against the patient's living will and become excessive medical intervention. However if the physician only listens to family member's opinion and can't get the patient's true wishes, coupled with an inability to help him or her make a decision in emergency circumstances, physicians often have to allow for insufficient intervention and surrender themselves to practical considerations such as avoiding medical risk and possible legal liability, Excessive medical intervention fundamentally violates the patient's right of choice based on the dignity of life, whereas insufficient intervention violates medical purposes of rescuing the dying. Both excessive intervention and insufficient intervention are all unjust procedures. For most patients' families, there are added difficulties. When they are asked to sign an informed consent, family members worry that the hospital will charge more or even perhaps shift the responsibility of failure onto them. Anyway, amid a backdrop of unsound health-care legislation, shaky economic liabilities and the hospital's patriarchal intervention policy, strictly speaking the autonomy of patients' families is severely distorted.

To sum up, in Europe and the United States the conflict between autonomy and medical intervention is mainly manifested by the struggle between a patient's excessive demands of autonomy (absolutizing autonomy) and an increasing shortage of medical resources. In China, the conflict between autonomy and medical intervention is mainly manifested by insufficient intervention due to incomplete medical legislation as well as traditional cultural factors. The diagnosis and treatment process in which doctors, patients, families and even the entire society should be working together against disease produces instead a conflict between patient autonomy and medical intervention, which makes the struggle between life and malady one of patients versus physicians.

Therefore, in China, respect for patient autonomy is not enough. More work is required to establish and improve medical legislation, really create and ensure all kinds of terms and conditions by which patient autonomy can be realized, and fundamentally eliminate unjust medical intervention. Only in this way can 
we move toward improving legislation, initiating living wills, and fully implementing the patient's informed consent, so as to contribute to the realization of true patient autonomy. The medical system must be revamped and a good relief system established so as to free the patient and family from unjust decisions which violate their economic condition. Such a medical makeover in China should strive to formulate a healthcare reform package with clear detailed provisions for medical responsibility and rights of all parties concerned with complete supervision and restrictions, in order to disentangle the profit mechanism from the operational process at medical institutions. Such provisions would help to eradicate the phenomenon of excessive and frequently unnecessary medical treatment, and help to establish the priority sequence of patients first and family second. Finally such reform should set up a medical advisory group on medical ethics in order to provide decision-making advice where patients lack the capacity to make a choice and provide a ruling opinion with explanatory power and credibility during doctor-patient disputes.

\section{Life Dignity and Humanistic Care: An Endless Thinking}

As I mention above, with different conflict forms between different cultural background notwithstanding, it is undeniable that the purpose of medical practice is the patient's well-being. Since it is so, why does conflict emerge in the medical field between autonomy and informed consent and Paternalism and doctor's intervention? Where is the real respect for and defense of the right to life? What conditions are required to support its implementation? Answering these questions will lead us into more in-depth thinking.

The principle of autonomy based on the justification of justice and rights, given the rise of autonomy, indicated the start of a new era of respect for individual rights in basic medical ethics. From the outset, the conceptual framework for bioethics accorded paramount status to the individual, underscoring principles of individual rights, autonomy, self-determination and their legal expression in the jurisprudential notion of privacy (Fox, 1990). These were the weapons required to attack and breach the citadel of medical paternalism that dominated the physician-patient relationship until at least the middle of the twentieth century. Nowadays, however, by absolutizing autonomy, excessive emphasis on individual independence brings about new problems to medical practice. Accompanied by the increasingly developed science and technology aimed at sustaining life and delaying death, the problem of futile medical care has caused widespread controversy and attention. In most European and American countries, there is relatively sound medical insurance, such that the main factors patients need to consider are personal willingness and medical technology, which is exactly why the excessive expansion of positive autonomy adds more pressure to the growing shortage of limited medical resources.

So, "medical futility" decisions justify the physician's right to refuse a patient's improper demands and provide an alternative solution for restraining the absolutizing of autonomy to better distribute often limited medical resources. That is 
to say, respect for patient autonomy doesn't means physicians have to accept all of the patient and their family member's demands, especially those requests which the medical team deem unreasonable or futile. If the patient asks for inappropriate or unnecessary medical treatment and the physician happens to agree with the patient, it will possibly result in a waste of medical resources, adding to the financial burden of health care so as to violate the principle of justice.

However, where limited medical resources exist, what physician decisions are reasonable and don't violate the principle of justice? For example, should we allocate the same amount of resources to every patient? Or should we allocate a few more resources to those patients who are more likely to be cured? Which is more just? This involves the trade-off between fair opportunity and the best treatment possible. When making a treatment decision, should physicians give prior consideration that benefit most patients or give prior consideration that benefit a few patients so as to maximize treatment results? This involves weighing medical comprehensive benefits. Again for instance, should we prioritize the maximum benefit of the current patient? Or should we prioritize social costs? An internal conflict occurs between two kinds of identities, one is the physician, the other is the social citizen.

In addition to facing complex decisions regarding principles of justice, the disputes surrounding "medical futility" mainly focus on judging the patient's quality of life. The core debate centers around "What kind of life deserves saving"? Both traditional ethics and our modern legal system stress the protection of human rights in believing that life is sacred and inviolable. No one can deny or deprive anyone of life no matter what kind of life (vegetable state, permanent coma, brain death). It is immoral and illegal to arbitrarily end life. An opposite point of view suggests that the value of life is not absolute and the meaning of life is not just being alive such that the recognition of the value of life should be based on both "sacred life" and "quality of life". As death inevitably comes and both the spirit and the body suffer from pain, the quality of life has been degraded, and the value and meaning of life has been lost. In these kinds of situation, abandoning treatment (even physician-assisted suicide) undoubtedly is an ideal way to respect life.

Although both views seem contradictory, when we examine them carefully, we find that the two views have the same theoretical foundation, namely respect and defense of abstract independent life itself which is sacred in the context of individualism. Respect for the life motivates people to save lives by all means and at all hazards. Also respect for the life calls on people to treat the living so well so as to make the already fragile suffer less pain as far as possible and maintain their dignity of life. I do not question the importance of autonomy in ethical conduct, I just want to say that a strong focus on making the right decisions is problematic, especially when combined with a tendency to stress the importance of patients' independence in choosing their treatment. It distracts attention from other important aspects of life and poses challenges to autonomy in health care. 
Firstly, there are many factors which obstruct the realization of patient autonomy. For those people who can't exercise their autonomy, can the physician's decision not to intervene be regarded giving up or not on the patient? Taking a closer look at autonomy, we find that there are certain obstacles may be involved. For example, by definition, "autonomy" must involve a human of "adult years," with a "sound mind." This brings in some constraints that need to be addressed except for the obvious age constraint. Terrence Ackerman in his 1982 report called "Why Doctors Should Intervene" gives light to various kinds of constraints. These constrains including Physical constraints (such as prison or bodily prevention); Cognitive constraints (without the ability to understand information; Psychological constraints (this would involve someone who is depressed or suffers from something like Alzheimer's disease) and Social cultural constraints (such as a peer pressure or the cultural background of a patient playing a role in autonomous decisions). When a patient has one or more of these constraints, perhaps the best way to make a decision concerning the welfare and needs of a patient is to allow for medical intervention.

Secondly, each patient is subject to specific health care system. If the design of the health care system can't provide basic medical security, how can patients achieve true autonomy? All people are created equal, and here equality means everyone has fundamental access to life dignity. However, in reality, all people are also not created equal, that is, one person may born in a rich family, possess good nutrition, good education and good health while another may born poor, suffer from malnutrition, congenital deficiency and illness. Factors vary from who gets sick, from what disease, with what kind of treatment and how many resources are available-all are unevenly distributed from person to person. Viewed from the egalitarian principle of justice, some basic equality should exist between people beyond the differences between them. So every person should have equal social and economic rights. Society should provide equal health care for each social member. Only by living in a society in which medical resource allocation is reasonable and all citizens are able to get the most basic medical security, can people truly make independent decisions. Only in this way, "a kind of consensus between doctor and patient based on social justice" (Buchanan, 2008) is likely to be really achieved.

Thirdly, each patient is not only a living person in the physical sense, but also in the spiritual one. A patient's life consists not only of a physical presence, but also of a spiritual dimension. During sickness or while dying, patients need more emotional care, the kind that families provide. They fear being abandoned by the world, abandoned by family, society and love. Therefore, is it a wrong assumption that each patient will want to choose by themselves? Perhaps patients are more willing to discuss medical treatment and medical decisions with their family and physician together in an atmosphere full of caring and love. However, dominated by contractual relationships, in the current medical practice, patients become "customers" and the doctor becomes a "service provider". In this kind of customer-service provider relationship, physician's rights of intervention are 
mainly based on consideration of market demand and pure medical technology. Although patients can also receive "care" in a purely technical health care system, if the "care" is due to "rights" and "consumer's choice", genuine warmth and emotional concern will be limited. Even if the patient chooses to terminate treatment in order to maintain the dignity of life, if their death is accompanied by disgust over impersonal medical apparatus and instruments, a sense of fear about death accompanied by mental and emotional stress, how can we say the patient has truly realized death with dignity? Death with dignity does not just mean a reduction of the pain of the body through medical treatment, or keeping the body intact, but it also means the elimination of the fear of death in an atmosphere of warmth and caring to allow the patient to face death without regret and walk to death with the warm memories and the glory of humanity. Only this manner of autonomy and intervention is real autonomy and real humanized intervention, just the kind of autonomy and intervention that can be called mutual respect for a complete life.

Therefore, it is still worthy of our thoughts to emphasize respect for the individual's equal independent status based on an abstract principle of justice (moreover the principle of justice itself is also controversial). Such a principle can properly characterize the special caring relationship between patient and physician. It's time to add medical background justice and emotional care into a philosophy of rights. Just think, if emotional care and love infiltrated the medical practice everywhere, would there still be serious conflicts between patients and physicians? On the contrary, if interventions are always filled with injustice and impersonal medical technology, no matter what kind of advanced treatment is being used, patients may be unable to truly experience the dignity of life.

\section{Conclusion}

In conclusion, for medical and health care professionals, the one-sided emphasis on insufficient intervention or excessive intervention in order to respect the autonomy of the patient may not qualify as the problem. The point of the problem is whether medical professionals should play a more active and determined role from the perspective of love and care in their work. It is also the physician's obligation derived from the physician's rights of medical intervention. But it should be pointed out that this kind of obligation pays more attention to construction and disentanglement which differs from traditional confrontation and treatment refusal. If we think of rights of intervention as a legal concept, the obligation derived from this kind of rights reflects more on the moral and humanistic concern. Also just for this reason, the more elastic the ethical decision model becomes (Tymchuk, 1981) the more people's concern is aroused in current medical practice.

Under this model, the key commitment in the development of medical science is by no means complete market operation and impersonal technical progress; on the contrary, the direction of medical science should return to its original "humanitarian" purpose of healing the wounded and rescue the dying. Of 
course, this will require us to ease out of contractual and utilitarian physician-patient relationships in diagnosis and treatment processes toward a medical diagnosis and treatment form that returns to its original purpose of public service. Only in this way may patients truly become a real subject free from a contractual relationship and responsible for their own life and social benefit. Families can then truly become strong supporters conducive to timely communication between physicians and patients and assist them in confronting disease together. The ideal physician-patient relationship is a kind of relationship in which each fully respects the autonomy of the other based on an unspoken covenant and bilateral trust between the doctor and patient.

That is to say, for the patient, the autonomy is not arbitrary autonomy, but a kind of responsible autonomy, namely responsible for each other in their relationships with others and with the society. When patients deeply feel sufficient care and love, it is possible to realize the ideal autonomy. For doctors, only by paying more attention to care for patients, will they reach that point of mutual respect, trust and cooperation with their patient. Also only like this, with a general shortage of medical resources, can autonomy and intervention, individual rights and public interest, all of these contradictions which seem full of conflict be managed to some degree of proper balance.

For each person, although it is impossible to choose a "good" birth, it is possible to choose a "good" death. So called "good" here is a kind of good based on justice and care. As Tagore had said, let life be gorgeous like summer flowers and let death be tranquility and beauty like autumn leaves, this is the true worship and praise for life.

\section{Fund}

This thesis is funded by the national social science foundation (14BKS008). Project title: Marxist critical justice theory and its contemporary value from the global perspective.

\section{References}

Beauchamp, T. L., \& Childress, J. F. (2001). Childress, Principle of Biomedical Ethics (5th ed., pp. 58-60). New York: Oxford University Press.

Beauchamp., T. L. \& Childress., J. F. (1989). Principles of Biomedical Ethics. New York: Oxford University Press.

Buchanan, D. R. (2008). Autonomy, Paternalism, and Justice: Ethical Priorities in Public Health. American Journal of Public Health, 98, 15-21.

Campbell, A. V. (1995). Health as Liberation (p. 14). Cleveland, OH: The Pilgrim Press.

Council of Europe (2009). Biomedicine and Human Rights: The Oviedo Convention and Its Additional Protocols.

Council on Ethical and Judician Affairs, American Medical Association (1999). Medical Futility in End-of-Life Care: A Report of the Council on Ethical and Judicial Affairs. JAMA, 281, 937-941. https://doi.org/10.1001/jama.281.10.937

Drane, J. F., \& Coulehan, J. L. (1993). The Concept of Futility. Patients Do Not Have a 
Right to Demand Useless Treatment. Health Progress, 74, 28-32.

Kolata, G. (1995). Court Ruling Limits Rights of Patients. The New York Times, April 22.

Milwaukee Journal (1975). Must Choose Life, Judge Says in Quinlan Decision. November 11, p. 8.

O’Neill, O. (2002). Autonomy and Trust in Bioethics. Cambridge: Cambridge University Press. https://doi.org/10.1017/CBO9780511606250

Opinion 2.035 Futile Care. American Medical Association. (2008). Code of Medical Ethics 2008-2009 Edition (pp. 13-15). Chicago, IL: American Medical Association.

Qiu, X. X., \& Sun, F. C. (2008). Medical Ethics. Beijing: People’s Medical Publishing House.

Rae, S. B., \& Cox, P. M. (1999). Bioethics: A Christian Approach in a Pluralistic Age. Critical Issues in Bioethics. Grand Rapids, MI: Eerdmans.

Shepherd, L. (2006). Terri Schiavo: Unsettling the Settle. Loyola University Chicago Law Journal, 37, 297-341.

Shuster, E. (1997). Fifty Years Later: The Significance of the Nuremberg Code. The New England Journal of Medicine, 337, 1436-1440.

Stirrat, G. M., \& Gill, R. (2005). Autonomy in Medical Ethics after O’Neill. Journal of Medical Ethics, 31, 127-130.

Truog, R. D. (2008). End-of-Life Decision-Making in the United States. European Journal of Anaesthesiology, 42, 43-50.

Tymchuk, A. J. (1981). Ethical Decision Making and Psychological Treatment. Journal of Psychiatric Treatment \& Evaluation, 3, 507-513. 